\title{
SUSTAINABLE ELECTRICITY GENERATION AND STORAGE MECHANISM THROUGH DOORS
}

\author{
Saud Sattar \\ Institute for Clean Growth and Future Mobility, Coventry University, \\ (United Kingdom). \\ E-mail: sattar5@uni.coventry.ac.uk \\ ORCID: https://doi.org/0000-0003-2477-0838
}

\begin{abstract}
Atif Saeed
Department of Mechatronics Engineering, SZABIST

Karachi, (Pakistan).

E-mail:m.atif@szabist.edu.pk

ORCID: https://doi.org/0000-0003-4369-2388
\end{abstract}

\begin{abstract}
Jane Proszek
Department of Electronic Engineering, University of York,

(United Kingdom).

E-mail: jane.proszek@york.ac.uk

ORCID: https://doi.org/0000-0002-1212-8920
\end{abstract}

Immar Khan

Department of Mechatronics Engineering, SZABIST

Karachi, (Pakistan).

E-mail: immarkhan@live.com

ORCID: https://doi.org/0000-0001-5748-1341

\section{Citación sugerida:}

Sattar, S., Saeed, A., Proszek, J., y Khan, I. (2022). Sustainable Electricity Generation and Storage Mechanism through Doors. 3C Tecnología. Glosas de innovación aplicadas a la pyme, Edición Especial, (febrero 2022), 197-207. https://doi.org/10.17993/3ctecno.2022.specialissue9.197-207 


\section{ABSTRACT}

The comfort associated with safety and convenience is here what man fought for. Our idea was to bring both. The culmination of our efforts has led to the us to create a way to utilize wasted physical energy convert it into usable energy and then save it efficiently. As today's world requires a lot of energy the various stages of their life. So, this idea is explanatory about the conversion of muscle strength into mechanical energy can also be converted into useful electricity power. This conversion can be done using a simple track and gear for the opening and closing op doors and generator (dynamo) to covert the motion of the gear on the track to usable electricity. The novelty of this scientific work is the implementation of four different types of batteries for on the same model to evaluate the system's autonomy and the efficiency of these battery types on a driving cycle, in real time.

\section{KEYWORDS}

Energy generation, Sustainable development, Gears, Track, Usable energy. 


\section{INTRODUCTION}

More and more engineers needed to play a leadership role in sustainable development, to challenge the global challenges, such as declining resources, pollution, rapid population growth and environmental damage. Looking at the problems facing our world today and the problems that are expected to arise in the first half of the twenty-first century, for engineers to revisit their thinking and adopt a new technology statement - to contribute to building a sustainable, stable and equitable land has become more critical. Since the industrial revolution the world is revolving around machinery and technology that has played a major role in energy consumption and carbon emissions and as our field, mechatronics, also relates to these works it is up to us to think and create a way for our world to be more sustainable. For out project the need for such design and production of a system, which will use free muscle power, to converts it into electricity. Electrical power is a basic and important requirement therefore must be a system present that can convert free energy into electricity power.

This thought essentially assists with capturing of the energy which is wasted while opening and shutting of the door. In this the angular motion of the entryway is changed over into rotatory movement. The rotatory motion is achieved by the gear that will be rotating on the track that is made and the motor coverts the rotatory motion into electricity. dynamo is an electrical generator that makes direct flow utilizing a commutator. The electric dynamo utilizes turning coil of wire and magnetic fields to change over mechanical pivot into a beating direct electric flow through Faraday's law of induction.

Household electricity consumption sector represents one of the main determinant factors of climatic changes, $23 \%$ of the greenhouse gas from the atmosphere coming from this sector. The goal is to reduce the emission of green-house gases and is achievable if the energy generated from sustainable sources are stored with maximum efficiency.

This study presents the autonomy of an Electric system that utilizes four different types of batteries: Lithium Ion (Li-Ion), Molten Salt (Na-NiCl2), Nickel Metal Hydride (Ni-MH) and Lithium Sulphur (Li-S), all of them having the same electric energy storage capacity. 


\subsection{BACKGROUND STUDY}

We combed through a number of research papers and selected a couple that were pertinent to our endeavor. Starting off with the first paper they are looking of necessity for creating and producing a system that will allow the Door to operate more freely, as well as converting the energy received by the generating system into electricity. We conclude that energy that is squandered in one way or another may be used to create electricity using a simple method. Because today's world is totally reliant on many forms of energies, all of which will vanish or exhaust at some point in the future, we must rely on free energy to power our fundamental gadgets that require electricity to function. The components they were using to create these were Gear Set, bearing, belt, LEDs, \& Dynamo.

In the second research, we have gone through the necessity for creating and producing a system that will allow the Door to operate more freely, as well as converting the energy received by the generating system into electricity. We discovered how genuine power may be created through the operation of the dynamo employed in the research. We were able to grasp the fundamental ideas of the components after going through the typical design methods they used in the project. We had a good understanding of and expertise with the model's manufacture and construction. We also learned an automated door function, which closed and opened the entrance. The components they used were fly wheel, rack, Spur Gear, Bevel Gear, Shaft, pulley \& V-belt.

In the third paper, this concept essentially conserves the muscular energy that is expended during opening and closing. The door's angular movement is translated into rotational motion in this way. The belt and pulley system is used to provide this rotational motion. Two pulleys are employed, one of which is larger and linked to the shaft that passes through the door hinges. The v-belt transmits power and motion from a larger pulley to a smaller pulley. The objective of a V-belt is to maintain a consistent spacing between the bigger and smaller pulleys. As a result, the door's angular movement is transformed to rotational motion, which is then passed on to the generator through the smaller pulley. We conclude that energy that is squandered in one way or another may be used to create electricity using a simple method. Because today's world is totally reliant on many forms of energies, all 
of which will vanish or exhaust at some point in the future, we must rely on free energy to power our fundamental gadgets that require electricity to function.

One advantage that our project has is that it can be attached to normal door without the need for extensive removal of door parts and further addition of new parts. The track will be attached to the wall above the door and the motor can be attached to the door itself with some object to align the gear to the track.

\section{METHODOLOGY}

For our parts we have used acrylic as a material as it has temperature tolerance of up to 170 to 190 degrees. The tensile strength of the material is 64.8-83.4 MPa, shear Modulus of 1.70 GPA and modulus of elasticity of 2.76-3.3 GPA. We also used this as it easier to cut and readily available and cheaper than other alternatives.

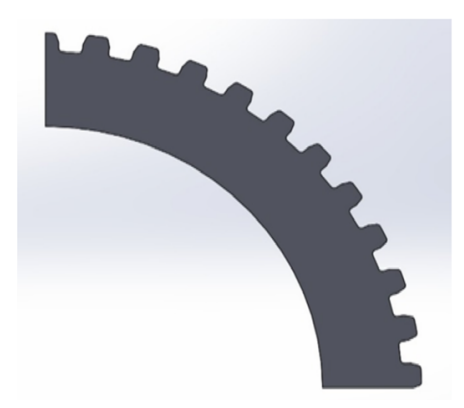

Figure 1. Rack Design.

Source: own elaboration.

Figure 2. Gear Design.

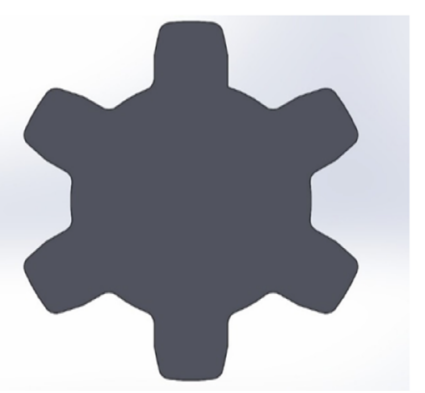

Source: own elaboration.

To make our project we had to create two parts firstly the track and the gear. We made our track which is a normal gear of diameter 19 inches, pitch diameter of 18.5 inches with 45 
teeth and diametral pitch of 2.43 inches. The circular gear was extrude cut to make a track of 90 degrees for the smaller gear to move on it.

The smaller gear which has pitch diameter of 2.5 inches, with 6 number of teeth and diametral of 2.4. the small gear is full spur gear which will be used to move on the track and rotate the pin of the motor. The small gear will be attached to the motor and the motor will be attached to the door as the door moves the gear will rotate about the track and the motor will generate electricity to light the led.

For the analysis we used alloy steel as it preferable to use steel as the material. We used acrylic as it would be cheaper and readily available for us. The acrylic pieces are strong as well and can withstand the force produced from pushing the door easily.

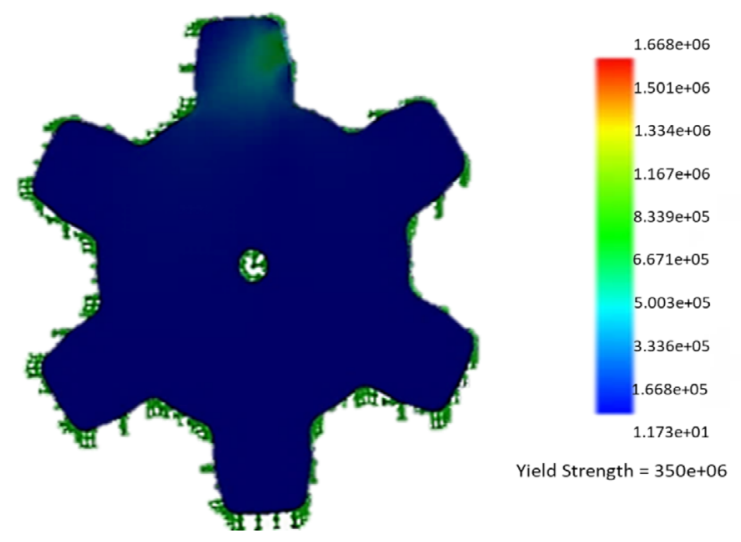

Figure 3. Gear Stress Analysis.

Source: own elaboration.

The electrical characteristics of all four battery types studied in this paper are presented in:

Table 1. Comparison of batteries.

\begin{tabular}{|c|c|c|c|c|c|}
\hline \multirow{2}{*}{ Name } & \multicolumn{4}{|c|}{ Value for Battery Type } & \multirow{2}{*}{ Unit } \\
\hline & Li-Ion & $\mathrm{Na}-\mathrm{NiCl}_{2}$ & Ni-MH & Li-S & \\
\hline Maximum Charge & 75 & 84 & 85 & 80 & $\mathrm{Ah}$ \\
\hline Nominal Voltage & 323 & 289 & 288 & 305 & V \\
\hline Stored Energy & 24.2 & 24.2 & 24.2 & 24.2 & $\mathrm{kWh}$ \\
\hline $\begin{array}{l}\text { Maximum Voltage / } \\
\text { Minimum voltage }\end{array}$ & $339 / 308$ & $275 / 304$ & $274 / 302$ & $290 / 320$ & V \\
\hline Initial Charge & 100 & 100 & 100 & 100 & $\%$ \\
\hline
\end{tabular}




\begin{tabular}{|c|c|c|c|c|c|}
\hline $\begin{array}{c}\text { Number of Cells per Cell-Row } \\
\text { Number of Cell-Row }\end{array}$ & 12 & 12 & 20 & 26 & - \\
$\begin{array}{c}\text { Internal Resistance charge / } \\
\text { discharge }\end{array}$ & 17 & 30 & 20 & 1 & $\Omega$ \\
\hline $\begin{array}{c}\text { Operating Temperature } \\
\text { Specific Heat Transition }\end{array}$ & 33 & $1 / 1$ & $1 / 1$ & $1 / 1$ & - \\
Specific Heat Capacity & 0.4 & 6 & 36 & 30 & $\mathrm{~W} / \mathrm{K}$ \\
\hline Mass of Battery & 795 & 950 & 670 & 0.08 & $\mathrm{~J} / \mathrm{kg}^{*} \mathrm{~K}$ \\
Battery Price & 318 & 457 & 534 & 1650 & $\mathrm{Kg}$ \\
\hline
\end{tabular}

Source: own elaboration.

\section{RESULTS}

From our project design we found that the gear is rotating almost 1.5 rotations. The voltage that we are generating is within a range of 1 volt to 0.1 volt depending on the amount of force you use to push the door. We took multiple calculations and found an average of 0.2 volts being produce while applying regular force to the door. We found that, even after applying as hard a force you can apply to the door, acrylic can handle these forces easily. If the voltage of 0.2 volts can be generated from one motion of opening the door, then for example if one person opens door let's say 20 times in a day then then one person can generate about 4 volts then one these mechanisms can be used in a university were 500's of people use one class room over a day then you can generate about 2000 volts in a day. If this mechanism is used in multiple doors of a university, building or a house then we can generate multiple volts in day.

The results of the four battery types obtained from hardware are presented in Figure 4. Total Output Energy $(\mathrm{kJ})$ and Total Input Energy $(\mathrm{kJ})$ results obtained, with all the four battery types, are presented in Figure 4. The results' analysis reveals that the recovered energy represents between 2 and $4 \%$ of the total consumed energy. 


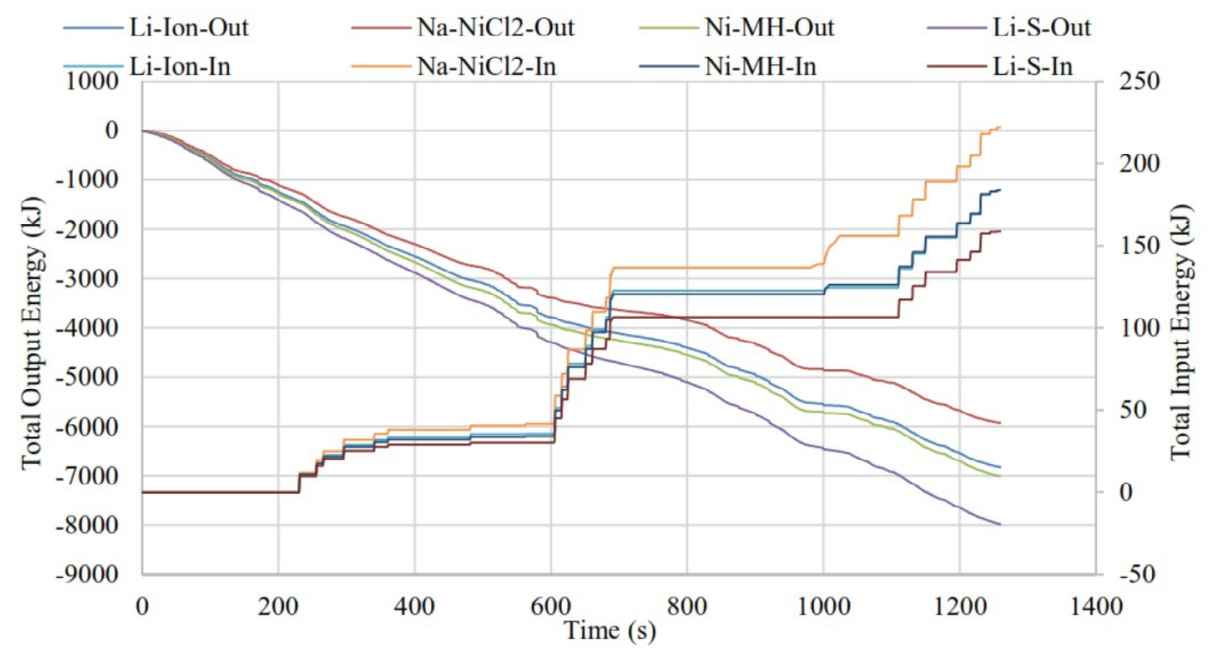

Figure 4. Comparison of Output and Input Energy. Source: own elaboration.

The Electrical Power $(\mathrm{kW})$ results, calculated, are presented in Figure 5. The power developed by the electric system (identical in all four cases) is similar for all four battery types, compared to the power values developed by the electric system powered by a Li-Ion battery, the Li-S batteries generate $0.5 \%$ less power, Na-NiCl2 generate $0.5 \%$ more power, and Ni-MH batteries generate $1.3 \%$ more power.

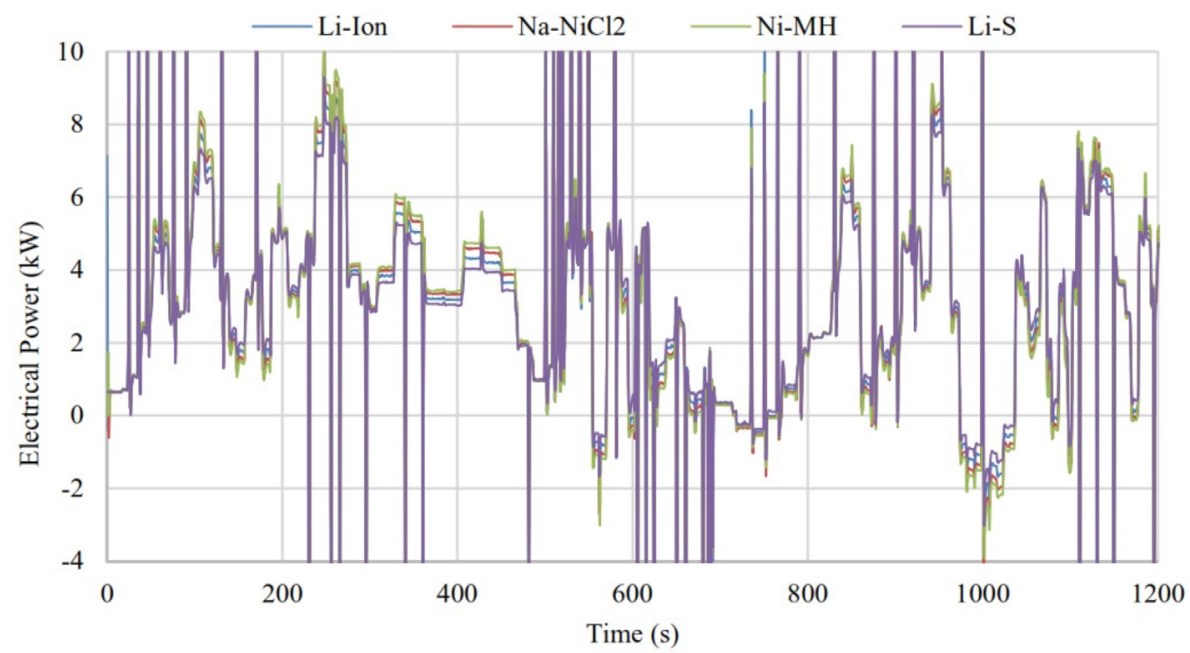

Figure 5. Power Comparison of Batteries.

Source: own elaboration. 


\section{CONCLUSIONS}

In our generation were the whole world and society have become dependent on power and with radical depletion of resources to produce power a way to introduce energy generation from everyday things like opening doors, that would normally have been wasted, can have a huge impact on our resources and carbon footprint as this energy that would be produced will have no repercussions, such as destroying the environment or adding to the already excessive greenhouse gases, can greatly benefit our world from the dangers of the ever depleting resources and can help with the sustainability of energy production, clean energy production. Our project can be further improved by introducing a way for the closing of the door to also generate power so energy can be made two ways rather than one. The number of teeth and gear ratio can further be improved so that the small gear makes more revolutions thus creating more electrical power.

Also, Na-NiCl2 batteries have proven to be the best choice from an energy consumption point of view. Besides that, other important advantages are their low price, increased lifecycle or great functioning under normal parameters in harsh environments. One disadvantage of these batteries is increased operating temperature, which is causing the battery electrolyte to solidify if the vehicle is not used. That is why, it is necessary to have one external system which maintains the battery's operating temperature under functional parameters.

\section{REFERENCES}

Ahamed, R., Rashid, M. M., Islam, J., Javed, A., \& Yusof, H. M. (2016). Energy generation from revolving door. Indian Fournal of Science and Technology, 9(19), 1-6. https://doi.org/10.17485/ijst/2016/v9i19/84237

Charbonneau, P. (2020). Dynamo models of the solar cycle. Living Reviews in Solar Physics, 17(4). https://doi.org/10.1007/s41116-020-00025-6

Junejo, F., Saeed, A., \& Hameed, S. (2018). 5.19 Energy Management in Ocean Energy Systems. In Comprehensive Energy Systems. Comprehensive Energy Systems, 5, 778-807. https://doi.org/10.1016/B978-0-12-809597-3.00539-3 
Kristyawan, Y., \& Rizhaldi, A. D. (2020). An Automatic Sliding Doors Using RFID and Arduino. International Journal of Artificial Intelligence $\mathcal{E}$ Robotics (IFAIR). https:// doi. org/10.25139/ijair.v2i1.2706

Longa, G. R., Ghung Kim Yuena, S., \& Nuricka, G. N. (2019). Analysis of a car door subjected to side pole impact. Latin American Fournal of Solids and Structures, 16(8). https://www.scielo.br/j/lajss/a/SmDN4GF6bGbsGZdPWTHCKKM/?lang=en

Partridge, J. S., \& Bucknall, R. W. G. (2018). Potential for harvesting electrical energy from swing and revolving door use. Cogent Engineering, 5(1). https://doi.org/10.1080 /23311916.2018.1458435

Rincon, F. (2019). Dynamo theories. Fournal of Plasma Physics, 85(4). https://doi. org/10.1017/s0022377819000539 
